\title{
Prosthodontic practice during the COVID-19 pandemic: prevention and implications
}

\author{
André Ulisses Dantas BATISTA ${ }^{(a)}$ \\ Pâmela Lopes Pedro da SILVA(a) \\ Laércio Almeida de MELO(b) ${ }^{(\mathrm{D}}$ \\ Adriana da Fonte Porto \\ CARREIRO(b) iD \\ (a) Universidade Federal da Paraíba - UFPB, \\ Health Sciences Center,Department \\ of Restorative Dentistry, João Pessoa, \\ PB, Brazil. \\ (b) Universidade Federal do Rio Grande do \\ Norte - UFRN, Department of Dentistry, \\ Natal, RN, Brazil.
}

Declaration of Interests: The authors certify that they have no commercial or associative interest that represents a conflict of interest in connection with the manuscript.

\section{Corresponding Author:}

Pâmela Lopes Pedro da Silva

E-mail: pamelapan_lopes@hotmail.com

https://doi.org/10.1590/1807-3107bor-2021.vol35.0049

Submitted: June 22, 2020

Accepted for publication: October 22, 2020

Last revision: January 29, 2021
Abstract: The objective of this review is to identify preventive measures for COVID-19 to safeguard dental professionals providing prosthodontic dental care. Electronic searches were performed in PubMed, Scopus, and Cochrane databases using the following descriptors and/or words: "COVID-19," "SARS-CoV-2," "Dental practice," "Prosthodontics," and "Dental infection control." Prosthodontists are at high risk for exposure to the novel coronavirus through aerosols and possibly contaminated surfaces and indirect contact with dental laboratories and dental technicians through impressions, dental stone casts, and fixed and removable prosthetic appliances. Therefore, preventive measures should be implemented, including performing emergency treatments only, rescheduling patients with suspected disease, disinfecting surfaces and prosthodontic materials with biocidal substances, and using protective equipment such as N95 masks, disposable gowns, and face-shields.

Keywords: COVID-19; Prosthodontics; Infection Control, Dental; Laboratories, Dental; SARS-CoV-2.

\section{Introduction}

Currently, we are being affected by the coronavirus disease (COVID-19) pandemic caused by Severe Acute Respiratory Syndrome Coronavirus 2 (SARS-CoV-2). ${ }^{1}$ As of October 27 th, there are more than 44 million confirmed cases and over 1,166,000 million deaths worldwide, with Brazil ranking the third and second highest position in the number of cases and deaths, respectively (https://coronavirus.jhu.edu/map.html). Therefore, individual and collective preventive measures are essential to contain the accelerated spread of this infectious disease. In dentistry, specifically in prosthodontic practice, professionals are exposed to infections through aerosol-generating dental equipment, such as high-speed rotation burs and air-water syringes, and through direct contact with an asymptomatic patient or with prosthodontic materials contaminated with saliva. ${ }^{1,2}$ Recently, the World Health Organization issued an alert about the possibility of COVID-19 transmission through air because droplets and aerosols generated during coughing or sneezing may remain suspended for a long time before entering the body through the respiratory tract or via ocular contact. ${ }^{2}$ 
The literature reports the need for preventive measures, such as new personal protective equipment (disposable gowns, face-shields, and N95 masks), constant hand washing, and surface disinfection with $70 \%$ alcohol. However, some recommendations are still controversial, such as a chlorhexidine rinse before dental treatment. ${ }^{1,2,3}$ Considering the need to establish preventive measures during prosthodontic oral rehabilitation care, the objective of the present study was to conduct a narrative and critical review of preventive measures for COVID-19 in prosthodontic dental care.

\section{Implications in prosthodontic practice}

From a prosthodontic point of view, some important issues must be considered. Prosthodontists are at a high risk of exposure to infection because of direct contact with patients during prosthetic treatment (aerosols formed during high-speed tooth preparation, exposure to saliva during conventional or digital impressions, contact with contaminated acrylic debris from dentures, or from finishing and polishing of temporary restorations, etc.) and indirect contact with dental laboratories and dental technicians, through impressions, dental stone casts, and fixed and removable prosthetic appliances. ${ }^{4}$ Therefore, a narrative and critical review of the literature was conducted to highlight protocols that may be useful in preventing COVID-19 spread in prosthodontic dental care. PubMed, Scopus, and Cochrane databases were searched using the following descriptors and/or words: "Covid-19," "SARS-CoV-2," “Dental practice," "Prosthodontics," and "Dental infection control."

\section{Saliva as a SARS-CoV-2 reservoir}

Composed of about $96 \%$ water, the human saliva also contains salivary gland excretions, food residues, serum components, microorganisms and their metabolites, and epithelial and white blood cell residues. Some studies showed that the main targets of SARS-CoV-2 are cells expressing the angiotensin-converting enzyme 2 (ACE 2), which is a crucial receptor for virus entry into the cell. In addition to alveolar epithelial cells, salivary gland epithelial cells also express ACE2. ${ }^{5}$ Thus, after the entry of the virus into the body, salivary gland epithelial cells can get infected, and the saliva produced by these glands can be an important source of cross infection. ${ }^{5}$

During prosthetic procedures, the clinician is subjected to direct and indirect contact with possibly contaminated saliva: directly, by handling of prostheses, trays, molds, high-speed handpieces, and dental instruments and indirectly through salivary aerosols produced during dental preparations. ${ }^{5,6}$ This direct contact with saliva by handling prostheses or dental instruments can be a source of indirect infection if the dental professional touches his/her oronasal mucosa or eyes with contaminated hands. Also, salivary aerosols suspended in air can directly contaminate the skin, eyes, or oronasal mucous membranes when inhaled. ${ }^{6}$

\section{Minimization of COVID-19 transmission in dental visits}

Pre-screening procedures are necessary to minimize the risk of a patient withSARS-CoV-2 visiting the dental office. These procedures consist of telephonic or video telehealth evaluation 24 to 48 hours before the patient's office visit. In these telehealth interactions, the following questions should be asked: "Have you had a fever, cough, or sore throat in the last 14 days?", "Have you had shortness of breath in the last 14 days?", and "Have you had close contact with people diagnosed with or under investigation for COVID-19 in the last 14 days?" 7 When affirmative answers are provided, the professional has the autonomy to reschedule these patients to avoid close contact with them. Ideally, such patients should be rescheduled after at least 14 days from the onset of these symptoms. ${ }^{7}$

\section{Interim guidance for emergency and urgent dental care management}

Dental care can be provided in cases of urgency and emergency. Some examples of urgent or emergency care in prosthodontics are provisional restoration debonding, prosthetic fractures, screw loosening in implant prostheses, and denture adjustments or repairs when function is impeded by pain or trauma. ${ }^{1,2}$ The recommended preventive measures during dental 
care in these cases are using dental handpieces with anti-retraction valves, four-handed dentistry with an assistant, high-volume saliva ejectors, using rubber dams in procedures that generate aerosols, using more stable elastomeric impression materials, as polyvinylsiloxanes, ordering laboratory-made $\mathrm{CAD} / \mathrm{CAM}$ provisional restorations to reduce clinical adjustments or additional appointments due to fractures, and asking the patients' companions to wait outside the clinic or inside their cars in the parking lots. ${ }^{1,2}$

In addition to these measures, it is recommended that patients rinse their oral cavity with $1.5 \%$ hydrogen peroxide or $0.2 \%$ povidone before each consultation. This measure is highly recommended when the use of rubber dams is not possible. In cases of pediatric patients who cannot rinse, the use of cotton rollers soaked with these solutions is recommended. ${ }^{8,9}$ However, it is worth noting that despite this recommendation given by the American Dental Association, a meta-analysis on the use of rinsing prior to dental care showed that it was effective in reducing the number of bacteria but not viruses. ${ }^{10}$ Some studies evaluating the action of these agents against SARS-CoV-2 demonstrated the effectiveness of povidone solution $(0.23 \%$ to $1 \%)$ and hydrogen peroxide $(0.5 \%)$ in inactivating the virus after one minute of use. However, this evidence has limited clinical significance, because these studies were only performed in vitro. $8,9,10$

\section{Importance of adequate personal protective equipment (PPE)}

Clinicians exposed to aerosols generated in dental care should use N95-type masks, waterproof disposable gowns, and face-shields, in addition to the PPE already used by these professionals (fabric gowns, cap, and gloves). ${ }^{1,2,3}$ The N95 mask is highly resistant to aerosols, with greater filtering capacity than the surgical mask. In case of respiratory secretions, viral particles can be found in aerosols (diameter $<5$ $\mu \mathrm{m})$ or droplets $(>5 \mu \mathrm{m})$. The N95 mask prevents the inhalation of $0.3 \mu \mathrm{m}$ particles by $95 \%$, whereas surgical masks filter particles $\geq 5 \mu \mathrm{m}$ from the air. ${ }^{11}$ In comparison, the face-shield aims to protect the whole face from aerosols generated during the care..$^{1,2,3}$
The use of disposable gowns over fabric gowns is essential to avoid contaminating the clothing used by the professional and that of the next patient to be treated. For this measure to be successful, the disposable gown should ideally be changed after each patient.

\section{Inactivation of coronaviruses on surfaces}

Large quantities of aerosols are produced during professional prophylaxis, and the use of rotary instruments for dental preparations, or the finishing and polishing procedures of saliva-contaminated prostheses. These aerosols can contain large ( $>5 \mu \mathrm{m}$ in diameter) and small $(\leq 5 \mu \mathrm{m}$ in diameter) particles. ${ }^{5.6}$ The large particles quickly descend to the ground due to gravity, while the smaller ones can travel distances of up to 1.5 meters, remaining viable and infectious for up to three hours suspended in the air. The estimated viral load in aerosols is variable. In patients breathing normally, the mean is 0.34 copies $/ \mathrm{cm}^{3}$ but can reach 11.5 copies $/ \mathrm{cm}^{3} .5,6$ When coughing, this viral load can reach 366,000 copies/ $\mathrm{cm}^{3}$. The use of air filters is recommended to prevent airborne SARS-CoV-2 infection. The high-efficiency particulate arrestance (HEPA) filter, which removes about $99.97 \%$ of particles measuring $0.3 \mu \mathrm{m}$ from the air, is an optimal choice. ${ }^{5,6}$

As aerosols are deposited on inanimate surfaces in the office, the use of biocidal agents on these surfaces is necessary; ${ }^{12}$ hence the interval between patients should be increased. ${ }^{1}$ Adequate time should be allowed to clean and disinfect the entire physical environment in which the dental procedures take place. ${ }^{1}$ To achieve this, the number of patients seen per day should be reduced. Among different biocidal agents, ethanol (78-95\%), propan-2-ol (70-100\%), $45 \%$ propan-2-ol associated with $30 \%$ propan-1-ol, gluataraldehyde (0.5-2.5\%), formaldehyde (0.7-1\%), and povidone-iodine $(0.23-7.5 \%)$ are shown to reduce infectivity of the coronavirus by about 10,000 times or more. Sodium hypochlorite is effective at a minimum concentration of $0.21 \%$. Hydrogen peroxide is effective at a concentration of $0.5 \%$ with an incubation time of one minute. In case of benzalkonium chloride, the data differ with respect 
to time. Within 10 minutes, the $0.2 \%$ concentration is not effective, while a $0.05 \%$ concentration is quite effective. Finally, $0.02 \%$ chlorhexidine di-gluconate is not effective to eliminate the coronavirus on surfaces. However, it is noteworthy that a concentration of $0.12 \%$ chlorhexidine seems to be effective for mouth rinses. ${ }^{12}$

\section{Social implications}

Considering the new necessary preventive measures and their greater frequency, increased costs are expected. One of the implications in Brazil, in the field of prosthodontics, will be limited access to prosthetic treatments. Epidemiologically, Brazil has high rates of edentulism. Due to future limitations on prosthetic treatment access, several people may have a decreased quality of life and masticatory capacity in the near future. ${ }^{13}$

\section{Conclusion}

To conclude, a prosthodontist is at high risk for exposure to the new coronavirus because of constant exposure to aerosols and possibly contaminated surfaces and indirect contact with dental laboratories and dental technicians through impressions, dental stone casts, and fixed and removable prosthetic appliances. Therefore, preventive measures should be implemented by these professionals, including performing emergency treatments only, rescheduling patients with suspected disease, disinfecting surfaces using biocidal substances, and using N95 masks, disposable gowns, and facial protectors.

\section{Acknowledgments}

We would like to thank Editage (www.editage.com) for English language editing.

\section{References}

1. Peng X, Xu X, Li Y, Cheng L, Zhou X, Ren B. Transmission routes of 2019-nCoV and controls in dental practice. Int J Oral Sci. 2020 Mar;12(1):9. https://doi.org/10.1038/s41368-020-0075-9

2. Izzetti R, Nisi M, Gabriele M, Graziani F. COVID-19 transmission in dental practice: brief review of preventive measures in Italy. J Dent Res. 2020 Aug;99(9):1030-8. https://doi.org/10.1177/0022034520920580

3. Spagnuolo G, De Vito D, Rengo S, Tatullo M. COVID-19 outbreak: an overview on dentistry. Int J Environ Res Public Health. 2020 Mar;17(6):1-4. https://doi.org/10.3390/ijerph17062094

4. Barenghi L, Barenghi A, Cadeo C, Di Blasio A. Innovation by computer-aided design/computer-aided manufacturing technology: a look at infection prevention in dental settings. BioMed Res Int. 2019 Aug;2019:6092018. https://doi.org/10.1155/2019/6092018

5. Li Y, Ren B, Peng X, Hu T, Li J, Gong T, et al. Saliva is a non-negligible factor in the spread of COVID-19. Mol Oral Microbiol. 2020 Aug;35(4):141-5. https://doi.org/10.1111/omi.12289

6. van Doremalen N, Bushmaker T, Morris DH, Holbrook MG, Gamble A, Williamson BN, et al. Aerosol and surface stability of SARS-CoV-2 as compared with SARS-CoV-1. N Engl J Med. 2020 Apr;382(16):1564-7. https://doi.org/10.1056/NEJMc2004973

7. Meng L, Hua F, Bian Z. Coronavirus disease 2019 (COVID-19): emerging and future challenges for dental and oral medicine. J Dent Res. 2020 May;99(5):481-7. https://doi.org/10.1177/0022034520914246

8. Bidra AS, Pelletier JS, Westover JB, Frank S, Brown SM, Tessema B. Comparison of in vitro inactivation of SARS CoV-2 with hydrogen peroxide and povidone-iodine oral antiseptic rinses. J Prosthodont. 2020 Aug;29(7):599-603. ; Epub ahead of print. https://doi.org/10.1111/iopr.13220

9. Yoon JG, Yoon J, Song JY, Yoon SY, Lim CS, Seong H, et al. Clinical significance of a high SARS-CoV-2 viral load in the saliva. J Korean Med Sci. 2020 May;35(20):e195. https://doi.org/10.3346/jkms.2020.35.e195

10. Marui VC, Souto ML, Rovai ES, Romito GA, Chambrone L, Pannuti CM. Efficacy of preprocedural mouthrinses in the reduction of microorganisms in aerosol: A systematic review. J Am Dent Assoc. 2019 Dec;150(12):1015-1026.el. https://doi.org/10.1016/i.adaj.2019.06.024

11. Liang M, Gao L, Cheng C, Zhou Q, Uy JP, Heiner K, et al. Efficacy of face mask in preventing respiratory virus transmission: a systematic review and meta-analysis. Travel Med Infect Dis. 2020 Jul - Aug;36:101751. https://doi.org/10.1016/i.tmaid.2020.101751

12. Kampf G, Todt D, Pfaender S, Steinmann E. Persistence of coronaviruses on inanimate surfaces and their inactivation with biocidal agents. J Hosp Infect. 2020 Mar;104(3):246-51. https://doi.org/10.1016/i.jhin.2020.01.022

13. Schwendicke F, Krois J, Gomez J. Impact of SARS-CoV2 (Covid-19) on dental practices: economic analysis. J Dent. 2020 Aug;99:103387. https://doi.org/10.1016/i.jdent.2020.103387 